\title{
A Feasibility Study on GlobalGAP Adoption among Small Farmers in
}

\section{Pakistan}

\author{
Muhammad Bilal Irshad ${ }^{1}$, MaimunahBinti Ali $^{2}$, AmjadMasood $^{3,}$ SamiullahSohu $^{4}$ \\ Faculty of Technology Management and Business, UniversitiTun Hussein Onn Malaysia (UTHM), Malaysia. \\ ${ }^{2}$ Faculty of Technology Management \& Business, University Tun Hussein Onn Malaysia (UTHM). Malaysia \\ ${ }^{3}$ Department of Management Sciences, KhwajaFareed University of Engineering and Information Technology, Rahim Yar Khan \\ (KFUEIT, RYK), Pakistan. \\ ${ }^{4}$ Department of Civil Engineering, QUEST Campus,Larkano, Pakistan.
}

\begin{abstract}
During the last couple of decades, certifications' role across the globe had taken a remarkable place with respect to meeting the international market demands for food security and safety. The study analyzes the cost structure of GlobalGAP adoption, identify various farm level factors that may affect a farmer's decision to get certified. Moreover, the study estimates the impact of certification on farm output. It has found that there is requirement to assess the properties of Global-GAP for Pakistani agriculture; to attain this a complete methodological idea is essential. This part will explain the analysis methods, research methodology, research design, and data collection. It would make the agriculture sector of Pakistan more export oriented, yielding higher returns to the gross domestic production of the county. In this context, the current study would yield a valuable guideline in order to reformulate policies that would ultimately help to improve global competency of agriculture sector of Pakistan. The benefit of this would be multifold. First, this would improve the livelihood conditions of the farming community. Secondly, adoption to good agricultural practices would contribute to food quality. And finally, it would make the agriculture sector of Pakistan more export oriented, yielding higher returns to the gross domestic production of the county.
\end{abstract}

Keywords

word; GlobalGAP; Certification; Adoption; Private Standards; smallholders; Farm Management the page size shouldbe A4.

\section{Introduction}

\subsection{Background}

Indeed, in Pakistan, agriculture sector is credited as backbone of its economy. Demands in Pakistan for more investments in the field of agriculture are increasing in view of very significance of its agriculture sector to achieve exponential growth in terms of farm's productivity and profitability. During the last couple of decades, certifications' role across the globe had taken a remarkable place with respect to meeting the international market demands for food security and safety [1]. However, the prevalence of GlobalGAP, a private food certification having international acceptability, is dismal in Pakistan. The focus of this study is on the matter of GlobalGAP adoption among farmers and comparative analysis of certified and noncertified farmers' profitability in Pakistan. To best of our knowledge, there has been no study in this area. As a matter of fact, compliance to any certification scheme such as GlobalGAP confers an adoption cost. In this way, the adoption may vary amongst large scale farmers and small land holders [2]. Potential findings of this study would help the Government to devise policies pertaining to agriculture sector in a way to facilitate small land holders to be beneficiary of the certification to enable them to access the international market while exporting their farm produce and earn more to contribute to the Gross Domestic Product of the country.

\subsection{Research objectives}

It is evident that the role of agriculture is significant in the economic uplift of the country. However, the situation of adoption to GlobalGAP or other relevant certification schemes is dismal. Considering the recent trends in agriculture production and trade, it is vital to shift policy aiming to render the agriculture sector competitive in the global context. In this way, the current study focuses on the idea of GlobalGAP certification. The study analyzes the cost structure of GlobalGAP adoption, identify various farm level factors that may affect a farmer's decision to get certified. Moreover, the study estimates the impact of certification on farm output. Specifically, the study formulates the following questions:

a) To analyze the cost structure of compliance to GlobalGAP certification in Pakistan.

b) To identify farm level factors affecting adoption of GlobalGAP certification in Pakistan.

c) To estimate economic gains associated with 
compliance to GlobalGAP certification in Pakistan.

\subsection{Definitions}

Global-GAP, formerly known as Europe-GAP, European-Retail Working Group established the Europe-GAP, formerly a corporation of Dutch, British and German exporter. From 15 more than 40 exporter, mostly Western European countries necessitate that their providers to be Global-GAP qualified. Initiative of British retailers only based on the BRC standard. In 1997/98 both standards initiated to be established and are including today apart from80 countries on all areas are certified manufacturers. In 2001 first cultivators were qualified with respect to the Europe-GAP. The BRC Food Technical Standard is focused towards processors as a post farm gate standard, Global-GAP directing the procedure of agricultural manufacture. So, fresh agricultural amount to be precisely provided to gastronomy or supermarkets can be approve by Global-GAP. Via labels on the product, both are not interconnected but are in chain standards to the buyer.

\subsection{Overview}

The rest of this article contains literature review, a research methodology that was accepted in this study.

\subsection{Literature review}

Incremental demand of private food standards in the international market has changed governing dynamics of the global agri-food value chains (Humphrey, 2014). It is happening in the developing countries where wholesalers to cater for the market demands are keen to observe private food standards up to the mark and the trend eventually moves down through well connected supply chain mechanism to the producer level. This is also blessing in disguise for the small land holding farmers in the developing countries that following the requirements of the standard, they are potentially viable to approach to global value chain, resultantly succeed to expose with novel economic avenues in the global market. Through adoption of the standards, benefits to farmers with small land holding while stepping into the global value chain are not limited to the extent of economic gains only but leave multiple effects of exploring new job opportunities and more income generation in the developing countries [1].

Besides, it is a matter of fact that the standards arise distinction in the farmer community with respect to their ability to cope with the standard requirements [3]. Ultimately, ones who are un-able to comply with the standards come out of the race of global export markets. Hence, the literature to modern global trade reveals scientific understanding of the significance of the application of standards how they facilitate and how they cause hurdles to international trade. This tells us with due justifications why we need to opt food standards. Demography, organizational working model and economic status of countries across the globe differ amongst them; so, as a matter of fact the capability [4].

and trend of adoption of the standards also vary amongst them. Likewise, several farm level and household level characteristics significantly affect the pace of adoption of standards within a country.

Primarily a pre-farm-gate process standard, GlobalGAP has increasingly been considered as a key reference for Good Agricultural Practice (GAP) for worldwide food safety affairs. GlobalGAP has been spreading worldwide rapidly with its current membership in 120 countries [5]. In this work, we study the issue of adoption of GlobalGAP in Pakistan. The study would have implications not only for Pakistan but also for other food exporting developing countries.

The agricultural sector plays an important role in most developing countries in terms of contributing to employment, income generation and food security. The importance of agriculture calls for an increase in investments in the sector to improve productivity and farm profitability. Similar to other developing economies, agriculture sector is the backbone of Pakistan's economy. In Pakistan, agriculture sector accounts for 19.5 percent of the gross domestic product and offers employment to 42.3 percent of the labor force [6]. Moreover, agriculture sector provides raw material for several value-added sectors. With an exponentially growing population, the country needs higher level of production for crops as well as for high-value perishable products such as fruits, vegetables, dairy, and meat. In this way, better policy decisions are required to make agriculture sector more productive.

In the recent decades, the rapid growth of Pakistan's urban areas indicates that demand for high-value perishable products such as fruits, vegetables, dairy and meat is rising. During 2016-17, agriculture sector of Pakistan achieved growth of 3.46 percent. The important crops including wheat, rice, sugarcane, maize and cotton account for 23.85 percent of the value added in overall agriculture and 4.66 percent of GDP. The Livestock accounts 58.33 percent share in the agriculture and it witnessed a growth of 3.43 percent. Fruits and vegetables are also an important subsector which constitutes to a 
considerable portion of agricultural exports of the country.

Compliance to standard is increasingly becoming important to compete in the international market. In South Asian region, China-Pakistan Economic Corridor (CPEC) is currently a mega project that includes several dimensions including infrastructural development and increased trade activity. In this scenario, the economic atmosphere in Pakistan is expected to be more internationalized. Given this, importance of certification would be more to various sectors of economy including agriculture.

\subsection{Compliance with food safety and quality standards}

With the increasing awareness of food safety and quality, especially in the developed countries, compliance with food safety and quality standards is becoming more and more important for current international agricultural trade. Therefore, it is important for food exporting countries to comply with the food safety certification schemes such as GlobalGAP. The current study aims to identification of farm characteristics as well as household characteristics which affect adoption process. The finding of this study can articulate policy guidelines to facilitate the adoption process of not only GlobalGAP scheme but also other food safety and quality standards such as British Retailers Consortium standard. Moreover, policy implications can be drawn for Pakistan in particular, developing countries in general, about farmers' capability to comply with standardization in order to compete for market access.

As a matter of fact, compliance to a certification scheme such a GlobalGAP requires an adoption cost. In this way, the adoption of GlobalGAP may vary among large scale farmer and small land holders. This potential finding imply that government would have to formulate agricultural policy in a way that it may support small land holders to be part of the certification in order to export their farm produce to high value export markets. Secondly, there comes the role of public private partnership as this may help to improve the pace of adoption to the certification schemes. Thirdly, it is the role of government agriculture extension department to provide latest machinery as well as appropriate trainings to help farmers so that they can shift from rational farming procedure to those required under certification schemes such as GlobalGAP.

\section{Research methodology}

Cost structure associated with compliance toand trend of adoption of the standards also vary amongst them. Likewise, several farm level and household level characteristics significantly affect the pace of adoption of standards within a country.

Primarily a pre-farm-gate process standard, GlobalGAP has increasingly been considered as a key reference for Good Agricultural Practice (GAP) for worldwide food safety affairs. GlobalGAP has been spreading worldwide rapidly with its current membership in 120 countries (GlobalGAP, 2017). In this work, we study the issue of adoption of GlobalGAP in Pakistan. The study would have implications not only for Pakistan but also for other food exporting developing countries.

The agricultural sector plays an important role in most developing countries in terms of contributing to employment, income generation and food security. The importance of agriculture calls for an increase in investments in the sector to improve productivity and farm profitability. Similar to other developing economies, agriculture sector is the backbone of Pakistan's economy. In Pakistan, agriculture sector accounts for 19.5 percent of the gross domestic product and offers employment to 42.3 percent of the labor force [6]. Moreover, agriculture sector provides raw material for several value-added sectors. With an exponentially growing population, the country needs higher level of production for crops as well as for high-value perishable products such as fruits, vegetables, dairy, and meat. In this way, better policy decisions are required to make agriculture sector more productive.

In the recent decades, the rapid growth of Pakistan's urban areas indicates that demand for high-value perishable products such as fruits, vegetables, dairy and meat is rising. During 2016-17, agriculture sector of Pakistan achieved growth of 3.46 percent. The important crops including wheat, rice, sugarcane, maize and cotton account for 23.85 percent of the value added in overall agriculture and 4.66 percent of GDP [7]. The Livestock accounts 58.33 percent share in the agriculture and it witnessed a growth of 3.43 percent. Fruits and vegetables are also an important subsector which constitutes to a considerable portion of agricultural exports of the country.

Compliance to standard is increasingly becoming important to compete in the international market. In South Asian region, China-Pakistan Economic Corridor (CPEC) is currently a mega project that includes several dimensions including infrastructural development and increased trade activity [8]. In this 
scenario, the economic atmosphere in Pakistan is expected to be more internationalized. Given this, importance of certification would be more to various sectors of economy including agriculture.

\subsection{Compliance with food safety and quality standards}

With the increasing awareness of food safety and quality, especially in the developed countries, compliance with food safety and quality standards is becoming more and more important for current international agricultural trade. Therefore, it is important for food exporting countries to comply with the food safety certification schemes such as GlobalGAP. The current study aims to identification of farm characteristics as well as household characteristics which affect adoption process [9]. The finding of this study can articulate policy guidelines to facilitate the adoption process of not only GlobalGAP scheme but also other food safety and quality standards such as British Retailers Consortium standard. Moreover, policy implications can be drawn for Pakistan in particular, developing countries in general, about farmers' capability to comply with standardization in order to compete for market access.

As a matter of fact, compliance to a certification scheme such a GlobalGAP requires an adoption cost. In this way, the adoption of GlobalGAP may vary among large scale farmer and small land holders. This potential finding imply that government would have to formulate agricultural policy in a way that it may support small land holders to be part of the certification in order to export their farm produce to high value export markets[10].

Secondly, there comes the role of public private partnership as this may help to improve the pace of adoption to the certification schemes. Thirdly, it is the role of government agriculture extension department to provide latest machinery as well as appropriate trainings to help farmers so that they can shift from rational farming procedure to those required under certification schemes such as GlobalGAP.

NTWK is a dummy variable whether the farmer is networked to ASF or other certification body (1 if networked, 0 otherwise).

\subsection{Impact of GlobalGAP certification on farm output}

I would use two estimation tools in this context. First, a t-test estimation in order to find where the mean output value between the two groups i.e. certified and non-certified farmers differs significantly [11]. Secondly, a regression analysis would be carried out to estimate the coefficient value for various regressors. Obviously the variable of interest in this regression would be the dummy variable of certification. An ordinary least square estimator will be applied in this section of estimation. We follow the approach applied by [12] in order to specify our model in this regard.

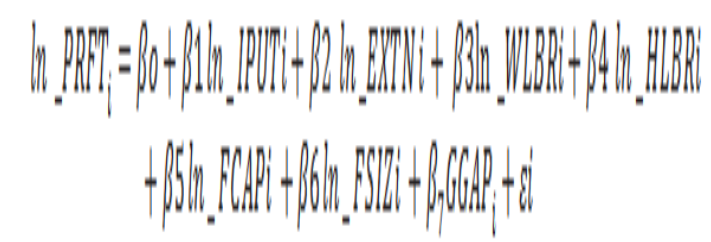

In the equation above, $\beta$ s are the parameters to be estimated, $\varepsilon$ demarks the regression error term. Other variables are labeled as follows:

In_PRFT is log of the normalized profit (in $1000 \mathrm{PKR}$ ) In_IPUT is log of the farm input prices (in $1000 \mathrm{PKR}$ )

ln_EXTN is $\log$ of the number of extension service (Number of visits)

ln_WLBR is log of the wages paid to farm labor (in 1000 PKR)

In_HLBR is the $\log$ of labor hours of household members (Hours)

ln_FCAP is $\log$ of the value of total fixed capital (in 1000 PKR)

$l n \_F S I Z$ is $\log$ of farm size (Acres)

$G G A P$ is dummy for GlobalGAP certified farmers (1 if certified, 0 otherwise)

NTWK is a dummy variable whether the farmer is networked to ASF or other certification body ( 1 if networked, 0 otherwise).

\subsection{Impact of GlobalGAP certification on farm output}

I would use two estimation tools in this context. First, a t-test estimation in order to find where the mean output value between the two groups i.e. certified and non-certified farmers differs significantly. Secondly, a regression analysis would be carried out to estimate the coefficient value for various regressors [13]. Obviously the variable of interest in this regression would be the dummy variable of certification. An ordinary least square estimator will be applied in this section of 
estimation. We follow the approach applied by [10] in order to specify our model in this regard.

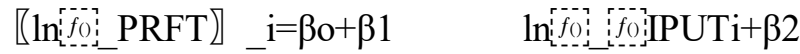

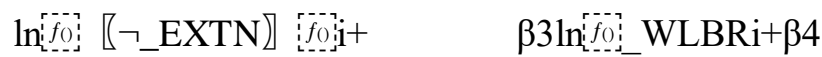

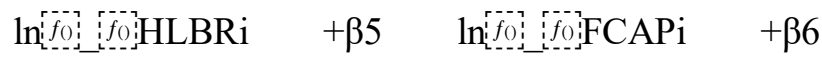

$$
\begin{aligned}
& \ln f_{-} f_{0} f_{0} \text { FSIZi }+\beta \_7 \text { [GGAP】_i+ci }
\end{aligned}
$$

In the equation above, $\beta \mathrm{s}$ are the parameters to be estimated, $\varepsilon$ demarks the regression error term. Other variables are labeled as follows:

ln_PRFT is $\log$ of the normalized profit (in 1000 PKR)

ln_IPUT is $\log$ of the farm input prices (in 1000 PKR)

ln_EXTN is $\log$ of the number of extension service (Number of visits)

ln_WLBR is $\log$ of the wages paid to farm labor (in 1000 PKR)

ln_HLBR is the log of labor hours of household members (Hours)

ln_FCAP is log of the value of total fixed capital (in 1000 PKR)

ln_FSIZ is log of farm size (Acres)

GGAP is dummy for GlobalGAP certified farmers (1 if certified, 0 otherwise)

\subsection{Data Survey}

Primary data would be collected by GlobalGAP certified farmers in various regions. For the sake of statistically sound estimation, non-adopter farmers would be surveyed in the corresponding regions. The GlobalGAP certified farmers which is the treatment group while the non-certified farmers would make the control group. Farmers in the control group will be selected through a random walk and chosen based on two criteria [14]. First, control group famers must be living in the same locality as the GlobalGAP adopters and second, they had to produce the products which are considered for GlobalGAP certification in that locality. Having the two groups, it would be possible to find the adoption as well the potential difference in the farm output associated with the certification. The study aims to collect the relevant data from 150 farmers across the country.

With the increasing awareness of food safety and quality, especially in the developed countries, compliance with food safety and quality standards is becoming more and more important for current international agricultural trade. Therefore, it is important for food exporting countries to comply with the food safety certification schemes such as GlobalGAP. The current study aims to identification of farm characteristics as well as household characteristics which affect adoption process [15]. The finding of this study can articulate policy guidelines to facilitate the adoption process of not only GlobalGAP scheme but also other food safety and quality standards such as British Retailers Consortium standard. Moreover, policy implications can be drawn for Pakistan in particular, developing countries in general, about farmers' capability to comply with standardization in order to compete for market access.

As a matter of fact, compliance to a certification scheme such a GlobalGAP requires an adoption cost. In this way, the adoption of GlobalGAP may vary among large scale farmer and small land holders. This potential finding imply that government would have to formulate agricultural policy in a way that it may support small land holders to be part of the certification in order to export their farm produce to high value export markets. Secondly, there comes the role of public private partnership as this may help to improve the pace of adoption to the certification schemes. Thirdly, it is the role of government agriculture extension department to provide latest machinery as well as appropriate trainings to help farmers so that they can shift from rational farming procedure to those required under certification schemes such as GlobalGAP.

\section{Concluding remarks}

In this context, the current study would yield a valuable guideline in order to reformulate policies that would ultimately help to improve global competency of agriculture sector of Pakistan. The benefit of this would be multifold. First, this would improve the livelihood conditions of the farming community. Secondly, adoption to good agricultural practices would contribute to food quality. And finally, it would make the agriculture sector of Pakistan more export oriented, yielding higher returns to the gross domestic production of the county.

\section{References}

[1] Melo, O., Engler, A., Nahuehual, L., Cofre, G., \&Barrena, J. (2014). Do sanitary, phytosanitary, and quality-related standards affect international 
trade? Evidence from Chilean fruit exports. World Development, 54, 350-359.

[2] Shahbaz, M. S., Mubarik, M. S., Mubarak, M. F., \&Irshad, M. B. (2019). The Impact of Lean Practices on Educational Performance: An Empirical Investigation for Public Sector Universities of Malaysia. Journal of Independent Studies and Research-Management, Social Sciences and Economics, 17(2), 85-96.

[3] Handschuch, C., Wollni, M., \& Villalobos, P. (2013). Adoption of food safety and quality standards among Chilean raspberry producers-Do smallholders benefit? Food Policy, 40, 64-73.

[4] GlobalGAP. (2017). Who We Are. Retrieved from http://www.globalgap.org/uk_en/who-we-are/

[5] Ministry of Finance. (2017). Pakistan Economic Survey 2016-17, Ministry of Finance, Finance Division. Government of Pakistan, Islamabad. Trotsuk, I., 2016, “To trust or not to trust" is not the question; "How to study trust" is much more challenging task', Russian Sociological Review 15(4), 57-75. https:// doi.org/10.17323/1728192X-2016-4-57-75

[6] Shahbaz, M. S., Shaikh, F. A., Qureshi, M. A., Jamali, Q. B., \&Sohu, S. (2019). The Influence of Supply Chain Collaboration on Supply Chain Performance for Malaysian Manufacturing Industry. Journal of Organizational Behavior Research, 4(2), 203-218.

[7] De Melo, J., \& Robinson, S. (2015). Productivity and externalities: models of export-led growth Modeling Developing Countries' Policies in General Equilibrium (pp. 43-70): World Scientific.

[8] Asfaw, S., Mithöfer, D., \&Waibel, H. (2010). What impact are EU supermarket standards having on developing countries' export of high-value horticultural products? Evidence from Kenya. Journal of International Food \& Agribusiness Marketing, 22(3-4), 252-276.

[9] Shahbaz, M. S., Othman, B. A., Salman, P. M., Memon, D. A., \&Rasi, R. Z. B. R. (2020). A Proposed Conceptual Action Plan for Identification, Assessment and Mitigation of Supply Chain Risks. Int. J. Advanced Operations Management, 12(1), 65-80.

[10] Ben-Akiva, M. E., \&Lerman, S. R. (1985). Discrete choice analysis: theory and application to travel demand (Vol. 9): MIT press.

[11] Chen, M. X., Otsuki, T., \& Wilson, J. S. (2006). Do standards matter for export success? World Bank Policy Research Working Paper (3809).

[12] Humphrey, J. (2014). Internalisation theory, global value chain theory and sustainability standards. International Business and Sustainable Development (Progress in International Business Research, Volume 8) Emerald Group Publishing
Limited, 8, 91-114.

[13] Kersting, S., \&Wollni, M. (2012). New institutional arrangements and standard adoption: evidence from small-scale fruit and vegetable farmers in Thailand. Food Policy, 37(4), 452-462.

[14] Williams, M., 2007, 'Building genuine trust through interpersonal emotion management: A threat regulation model of trust and collaboration across boundaries', The Academy of Management Review 32(2)Gusev A A et al 2011 J. Phys.: Conf. Series 291012052.

[15] Virues, C., Velez, M. \& Sanchez, J.M., 2019, 'Entrepreneurs as trust's builders: An integrated model', Open Journal of Business and Management 7(3), 1298-1337. https://doi.org/10.4236/ojbm.2019.73091 